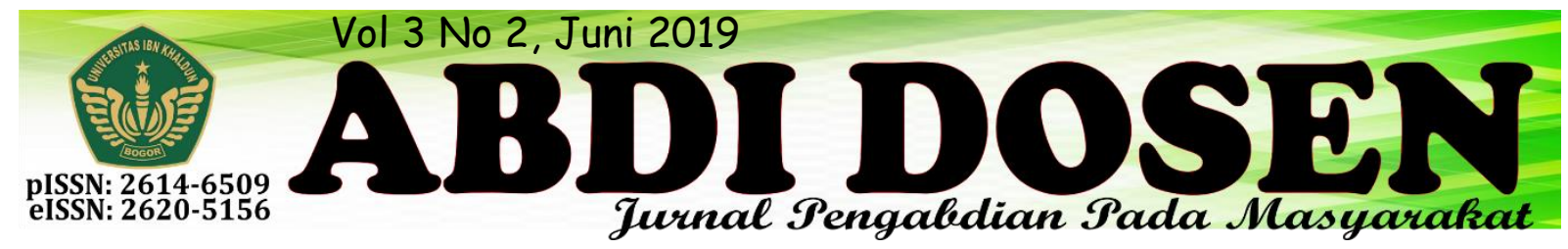

\title{
PENINGKATKAN OPTIMALISASI POLA HIDUP DAN LINGKUNGAN SEHAT MASYARAKAT DI DESA CIBATOK DUA
}

\author{
Asri Masitha Arsyati ${ }^{1}$, Sarbini, Irma Sartika ${ }^{2}$ \\ asri.masitha@gmail.com \\ Fakultas Ilmu Kesehatan Universitas Ibn Khaldun ${ }^{1}$, Mahasiswa KKN Kelompok 25 Tahun $2018^{2}$
}

\begin{abstract}
ABSTRAK
Mahasiswa mempunyai peranan stategis sebagai agen perubahan, kuliah Kerja Nyata (KKN) merupakan salah satu bentuk pengabdian mahasiswa perguruan tinggi kepada masyarakat melalui pemberian bantuan pemberdayaan, pelatihan, penyuluhan, bimbingan, pendampingan dan untuk menyadarkan potensi yang dimiliki, serta membantu meningkatkan dan kualitas hidup dan pembangunanmahasiswa akan mendapatkan kemampuan generatif berupa life skill. Observasi dilakukan dengan cara silaturrahim, wawancara, dokumentasi, dan melihat langsung kondisi lapangan. Berdasarkan observasi maka selaku mahasiswa yang ditempatkan di Desa Cibatok Dua dapat, diantara beberapa program yang ditentukan oleh kelompok KKN 25 antara lain, bidang pendidikan, bidang ekonomi, bidang kesehatan, dan bidang lingkungan yang dapat dilaksanakan di Desa Cibatok dua RW 07 dengan melihat kondisi masyarakat dan keadaan yang mendukung, program pendidikan turut serta dalam kegiatan belajar mengajar di lembaga lembaga pendidikan yang ada di Desa Cibatok Dua, mulai dari PAUD, SDN, dan MI. Program kesehatan yaitu senam sehat, emo demo , program ekonomi yaiti memberikan penyuluha tentang pentingnya menabung sejak usia dini, adapun yang berkaitan dengan lingkungan yaitu dengan memberikan 1000 pohon untuk penghijauan lingkungan sekitar
\end{abstract}

\section{Kata Kunci: Lingkungani, Hidup, Sehat}

\section{PENDAHULUAN}

Berdasarkan hasil observasi yang dilakukan oleh KKN 25 didapati permasalahan dasar di desa tersebut. Permasalahan yang ada pada lingkungan desa Cibatok Dua ialah minimnya kesadaran masyarakat akan pentingnya pola dan gaya hidup sehat, serta kurangnya pengetahuan tentang pengelolaan limbah masyarakat.

Pada bidang ekonomi, dengan minimnya home industri yang menjadi penghambat tumbuh kembangnya ekonomi masyarakat.

Sedangkan pada bidang kesehatan, pola hidup sehat masih jauh dari

diterapkan. Pola hidup yang masih tradisional yang mengandalkan ilmu kesehatan sederhana membuat masyarakat seringkali mengabaikan kesehatan dirinya dan kurangnya perhatian masyarakat terhadap kesehatan anak-anak.

Dan bidang lingkungan, lingkungan yang ada di Kampung Cibereum kurangnya sarana dan prasarana penanggulangan limbah masyarakat, pembuangan MCK, sering kali sampahsampah berserakan di lingkungan dan juga sering terjadi banjir. 


\section{Geografis}

Desa Cibatok Dua merupakan bagian dari Kecamatan Cibungbulang, Kabupaten Bogor, Provinsi Jawa Barat. Luas wilayah Desa Cibatok Dua adalah 177,168 Ha. Pelaksanaan KKN Universitas Ibn Khaldun Bogor kelompok 25 ditempatkan di lokasi Kp. Cibereum RW 07 yang berjumlah 3 RT (RT 01, RT 02, RT 03) Secara geografis Desa Cibatok Dua berada di Kecamatan Cibungbulang, Kabupaten bogor, Provinsi Jawa Barat yang meliputi:

Peta Lokasi

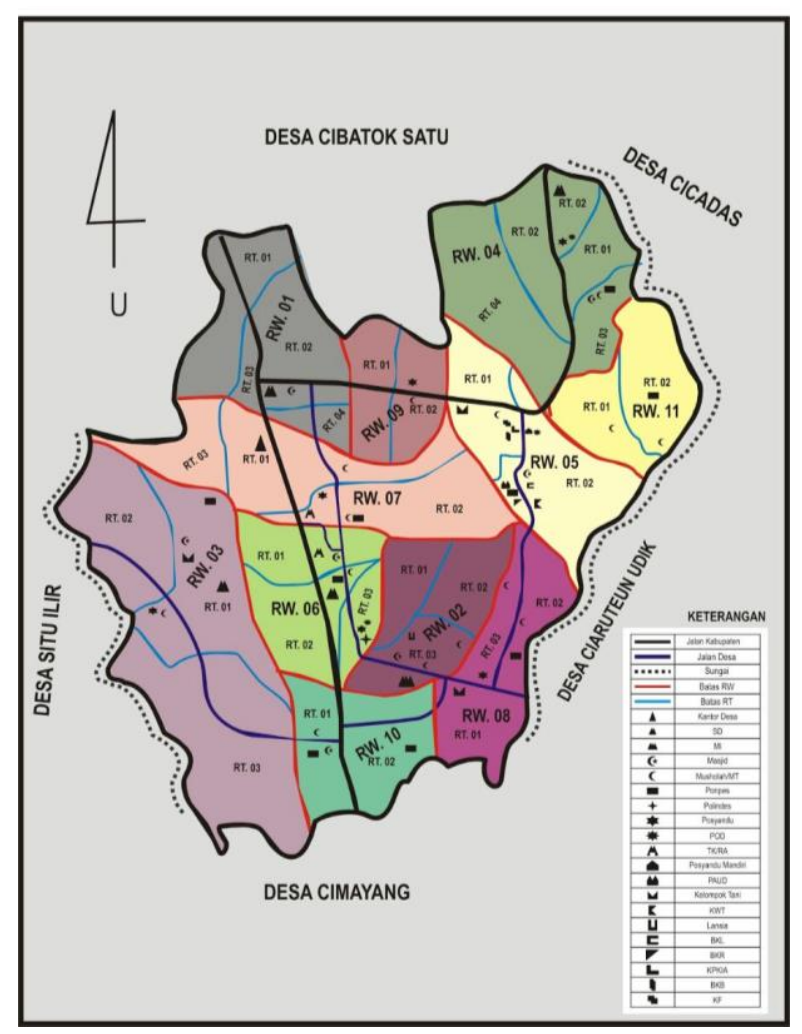

Batas Wilayah

\begin{tabular}{|c|l|c|}
\hline No & Arah & Berbatasan \\
\hline 1 & Utara & Desa Cibatok Satu \\
\hline 2 & Selatan & Desa Cimayang \\
\hline 3 & Barat & Sungai Situ Ilir \\
\hline
\end{tabular}

\begin{tabular}{|c|l|c|}
\hline 4 & Timur & Desa Cicadas \\
\hline
\end{tabular}

\section{Topografi Desa}

Secara umum keadaan topografi

Desa Cibatok Dua adalah daerah daratan rendah. Suhu rata-rata Desa Cibatok Dua berkisar $28{ }^{\circ} \mathrm{C}-33{ }^{\circ} \mathrm{C}$. Desa Cibatok Dua terdiri dari 11 rukun warga (RW). Iklim di Desa Cibatok Dua, sebagaimana desa desa lain di wilayah Indonesia mempunyai iklim kemarau dan penghujan. Iklim yang memengaruhi desa Cibatok Dua.

\section{Demografi}

Kondisi sosial Desa Cibatok Dua terdiri dari masyarakat asli (pribumi) yang ditambah dengan penduduk pendatang.

Desa Cibatok Dua terdiri dari :

Kependudukan

\begin{tabular}{|c|l|c|}
\hline No & Jenis Kelamin & Jumlah \\
\hline 1 & Laki-laki & 3770 \\
\hline 2 & Perempuan & 3720 \\
\hline
\end{tabular}

\section{Pendidikan}

Sumber Daya Manusia (SDM) yang ada di wilayah Desa Cibatok Dua Kecamatan Cibungbulang, mempunyai potensi yang sangat baik untuk memajukan pembangunan infrastruktur maupun dalam membantu perkembangan dan pertumbuhan perekonomian masyarakat. Adapun fokus perkembangan dan pertumbuhan perekonomian dikhususkan di bidang pertanian, peternakan, Kelompok Usaha Tani, dan usaha-usaha lainnya. Hal ini disebabkan karena mata pencaharian Desa Cibatok Dua adalah petani, dan peternak 
METODE PENGABDIAN

\section{Tahap Pelaksanaan}

Tahapan pelaksanaan untuk kegiatan ini sebagaimana terlihat pada bagan sebagai berikut:

\begin{tabular}{|c|l|c|c|c|c|}
\hline \multirow{2}{*}{ NO } & \multicolumn{2}{|c|}{ NAMA KEGIATAN } & \multicolumn{4}{c|}{ MINGGU KE- } \\
\hline & & 1 & 2 & 3 & 4 \\
\hline 1 & Sosialisasi dengan Masyarakat & & & & \\
\hline 2 & $\begin{array}{l}\text { Bimbingan Belajar (Bahasa } \\
\text { Inggris, Matematika) }\end{array}$ & & & & \\
\hline 3 & Edukasi Teknologi & & & & \\
\hline 4 & Kegiatan Keagamaan & & & & \\
\hline 5 & Mengajar Mengaji & & & & \\
\hline 6 & Bimbingan Ibadah Amaliah & & & & \\
\hline 7 & Senam Sehat & & & & \\
\hline 8 & Kampung Sehat & & & & \\
\hline 9 & Pentas Seni Hut RI 73 & & & & \\
\hline 10 & Mengajar di PAUD A1-Ghozali & & & & \\
\hline 11 & $\begin{array}{l}\text { KBM di SDN Cibatok 02 dan MI } \\
\text { Sirojusshibyan }\end{array}$ & & & & \\
\hline 12 & Pemeriksaan Kesehatan Gratis & & & & \\
\hline 13 & Penyuluhan Menabung Sejak Dini & & & & \\
\hline 14 & $\begin{array}{l}\text { Penyuluhan CTPS (Cuci Tangan } \\
\text { Pakai Sabun) }\end{array}$ & & & & \\
\hline 15 & $\begin{array}{l}\text { Pengembangan Metode } \\
\text { Pengajaran dengan Metode } \\
\text { "Belajar Sambil Bermain" }\end{array}$ & & & & \\
\hline 16 & Praktik Ekonomi Kreatif & & & & \\
\hline 17 & $\begin{array}{l}\text { Praktik CTPS (Cuci Tangan Pakai } \\
\text { Sabun) }\end{array}$ & & & & \\
\hline 18 & $\begin{array}{l}\text { Penyuluhan Pola Makan Sehat Ibu } \\
\text { Hamil }\end{array}$ & & & & \\
\hline 19 & $\begin{array}{l}\text { Penyuluhan Stunting di Posyandu } \\
\text { RW 07 }\end{array}$ & & & & \\
\hline 20 & Pemberian 1000 Bibit Pohon & & & & \\
\hline
\end{tabular}


Metode Pendekatan

\section{Pendekatan Sosial}

Pendekatan Sosial yang dilakukan dalam masyarakat RW 07 Desa Cibatok Dua, Kecamatan Cibungbulang, yaitu dengan mengintegrasikan diri (meleburkan diri) ke dalam berbagai kegiatan masyarakat agar dapat diterima dan berperan serta dalam berbagai kegiatan masyarakat di RW 07 Desa Cibatok Dua. Pendekatan Sosial juga dilakukan pada saat perencanaan kegiatan, pelaksanaan kegiatan, maupun evaluasi kegiatan. Dalam tahap perencanaan, pendekatan sosial dilakukan dengan berusaha melibatkan masyarakat, baik secara langsung, maupun tidak langsung, dalam penyusunan rencana atau program kegiatan KKN. Dengan partisipasi masyarakat dalam perencanaan, kita dapat mengidentifikasi berbagai kebutuhan dan permasalahan nyata yang dihadapi masyarakat, sehingga kita dapat menyusun action plan yang lebih tepat dan realistis. Semakin banyak masyarakat yang dilibatkan tentunya akan semakin baik. Di samping itu keterlibatan masyarakat dalam perencanaan dapat membawa efek psikologis kepada mereka untkuk samasama memikul tanggung jawab dalam mengimplementasikan rencana-rencana yang telah dibuat.

Pendekatan sosial dalam tahap pelaksanaan, terutama dilakukan de ngan cara membangun komunikasi dan hubungan sosial yang harmonis untuk secara bersama mengimplementasikan setiap rencana yang telah disusun. Dibandingkan dengan tahapan KKN yang lainnya inilah pendekatan sosial memegang peranan penting dan harus banyak dilakukan oleh peserta KKN.

Sedangkan pendekatan sosial dalam tahap evaluasi berkaitan erat dengan partisipasi masyarakat untuk memberikan data yang obyektif atas kegagalan dan keberhasilan kegiatan KKN.

\section{Pendekatan Berdasarkan Karakter Masyarakat}

Pendekatan berdasarkan karakter masyarakat, yakni pembinaan yang dilakukan akan disesuaikan dengan karakter masyarakat. Joyce dan Weil (1996) mengungkapkan bahwa model pendidikan yang relevan dengan perilaku sosial dan nilai adalah dengan banyak memberikan permainan peran. Hal ini dilakukan untuk memberi pengalaman riil kepada peserta didik tentang sesuatu yang dilakukan atau dirasakan oleh orang lain. Memang, dalam prakteknya, tidak seluruh aspek harus menggunakan permainan ini. Dalam beberapa hal, terdapat kegiatankegiatan yang hanya golongan tertentu untuk melakukannya. dapat digunakan untuk membangun kesadaran toleransi masyarakat. Hal ini karena penekanan dari konsep pendidikan ini adalah kerjasama yang merupakan urat nadi toleransi. Dengan demikian, model pendidikan yang akan dibangun menggunakan dua konsep utama yaitu role playing model dan cooperative learning model. Selain dua meodel diatas diperkuat dalam Wang, C.X Victors (2014), teori pendidikan kesehatan yang diberikan pada masyarakat dan usia dewasa lebih menekankan pada upaya keterlibatan masyarakat dalam merubah sesuatu sesuai kebutuhan atau kepentingannya.

\section{Partisipasi Masyarakat dalam Pelaksanaan Program}

Partisipasi masyarakat yang dapat dilakukan dalam kegiatan ini adalah sebagai berikut:

1. Mengikuti setiap kegiatan yang terdapat dalam program kerja $\mathrm{KKN}$ Kelompok 25

2. Membantu dalam kegiatan baik secara materi atau non-materi 
3. Tidak menggangu selama kegiatan berlangsung

4. Recpect pada setiap kegiatan yang diadakan

\section{Langkah Evaluasi}

Evaluasi yang akan dilakukan terdiri dari:

Evaluasi proses, yang terkait dengan perencanaan, pelaksanaan dan monitoring

\section{REALISASI PROGRAM}

Berikut adalah capaian program yang telah dilaksanakan :

\section{Bidang Ekomomi dan Pemberdayaan}

Masyarakat

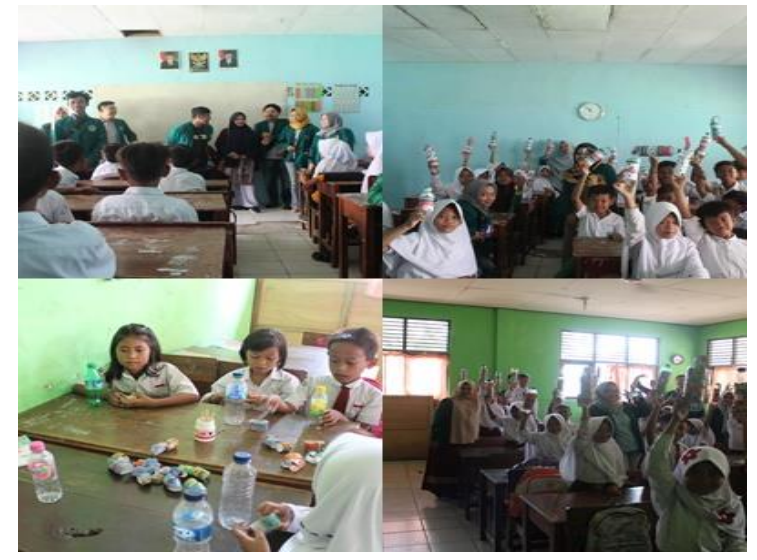

a. Penyuluhan Menabung Sejak Dini dan Praktik Ekonomi Kreatif

Capaian program dari Penyuluhan Menabung Sejak Dini dan Praktik Ekonomi Kreatif ialah dihadiri 152 murid. Beberapa di antara yang hadir adalah murid SDN Cibatok 02 dan MI Sirojusshibyan. kegiatan. Evaluasi proses akan dilakukan setiap pekan bersama dengan masyarakat.

Evaluasi hasil, yang akan dilaksanakan setelah kegiatan dilaksanakan. Evaluasi hasil ditujukan untuk menguji pemahaman masyarakat terhadapat kegiatan atau materi yang telah diberikan.

\section{Bidang Kesehatan dan Lingkungan}

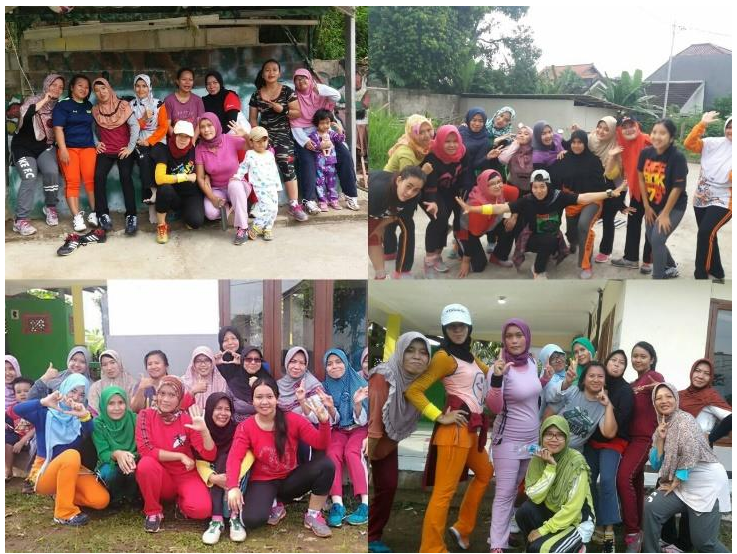

a. Senam Sehat

Capaian program dari senam sehat ialah partisipasi masyarakat yang ikut serta dalam kegiatan senam sehat yang cukup banyak.

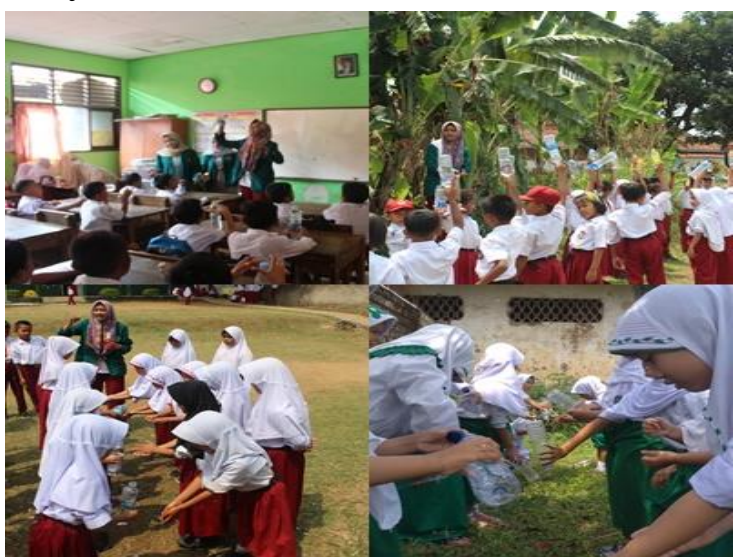

b. Penyuluhan dan Praktik CTPS (Cuci Tangan Pakai Sabun)

Capaian program dari Penyuluhan dan Praktik CTPS (Cuci Tangan Pakai Sabun) ialah antusias siswa-siswi dalam kegiatan penyuluhan sangat baik. Siswa-siswi selalu menanggapi pertanyaan dari pemateri. 


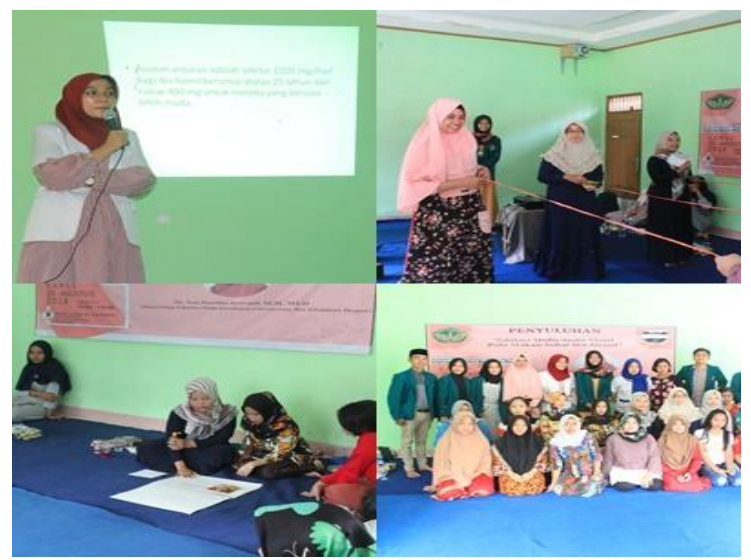

c. Penyuluhan Pola Makan Sehat Ibu Hamil

Capaian dari program Penyuluhan Pola Makan Sehat Ibu Hamil ialah dihadiri oleh 21 ibu hamil. Dari 21 ibu hamil yang menghadiri penyuluhan tersebut, $100 \%$ sudah mengetahui dan memahami jenis makanan yang sehat bagi ibu hamil dan kebutuhan asupan gizi bagi ibu hamil.

\section{Bidang Pendidikan}

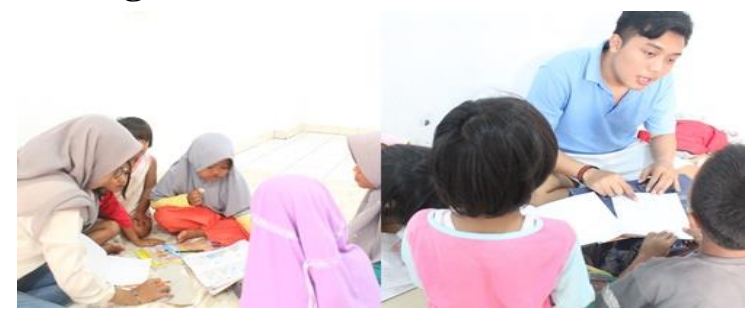

a. Bimbingan Belajar

Capaian program dari bimbingan belajar ialah diikuti lebih dari 50 anak. Dan materi yang diajarkan dalam Bimbingan Belajar adalah Agama Islam, Ibadah maliyah, Calistung (Baca Tulis Menghitung), dan Bahasa Inggris.

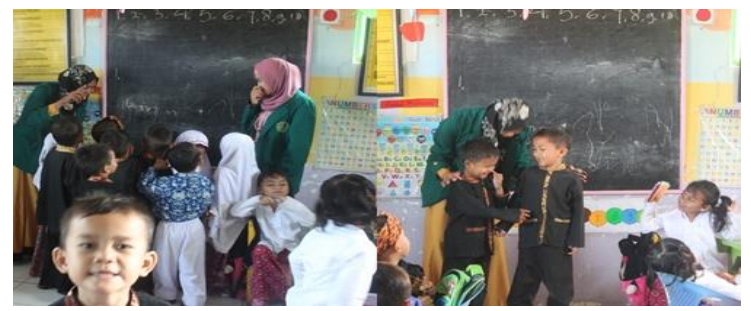

b. Pengembangan Metode Pembelajaran dengan Metode "Belajar Sambil Bermain"

Capaian program ini ialah diikuti oleh 150 siswa-siswi PAUD Al-Ghozali,
SDN Cibatok 02 dan MI

Sirojusshibyan.

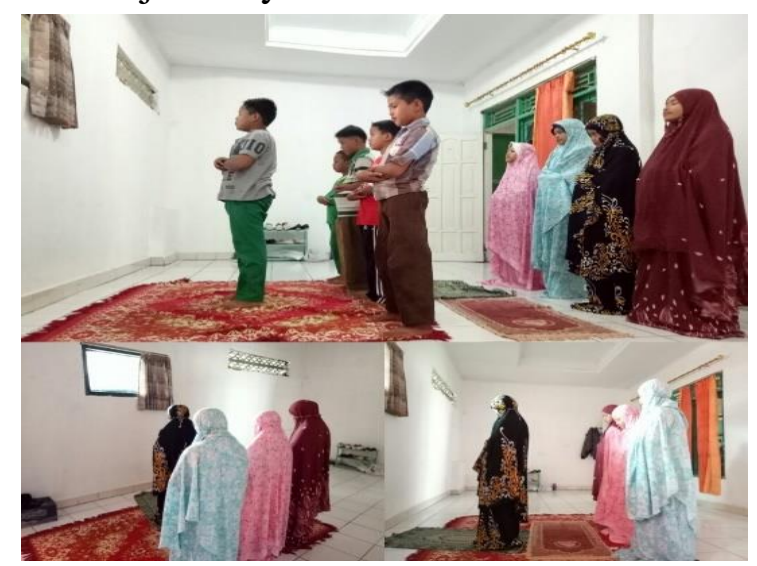

c. Bimbingan Ibadah Amaliah

Capaian program ini ialah telah diikuti oleh siswa-siswi kelas 3-6 SD yang pelaksanannya pada sore hari hari menjelang maghrib, sebagai indikator terealisasinya program Bimbingan Ibadah Amaliyah ini yaitu para peserta didik telah mampu dan menguasai tatacara dan adab adab serta bacaan bacaan dalam ibadah amaliyah.

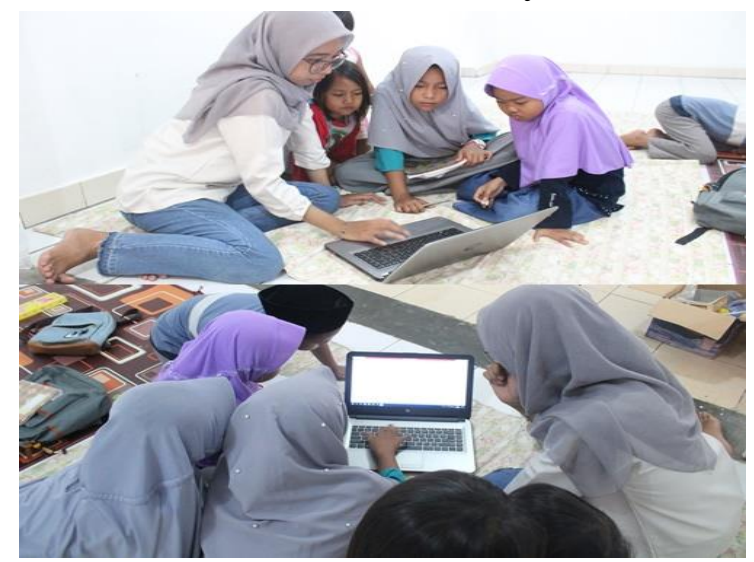

d. Edukasi Teknologi

Capaian program ini ialah diikuti oleh lebih dari 50 orang, yang merupaka siswa dan siswi SD/sederajat yang ada di sekitar posko KKN 25. 


\section{KESIMPULAN}

Kuliah kerja Nyata $(\mathrm{KKN})$ adalah suatu sistem yang terdapat di dalam pendidikan tingkat tinggi (perguruan tinggi) dimana mahasiswa ditempatkan pada masyarakat yang dirasa membutuhkan perubahan untuk membantu dan mendampingi masyarakat, memanfaatkan potensi yang dimiliki oleh masyarakat.

Desa Cibatok Dua yang memiliki potensi yang banyak, namun pengelolaannya belum memadai. Sehingga kami berpikir bahwannya masyarakat di Desa Cibatok Dua ini membutuhkan banyak pembinaan baik dari segi Penddikan, Ekonomi, Kesehatan dan lingkungan

Berikut adalah dampak bagi masyarakat berdasarkan program kerja yang telah dilaksanakan :

\section{Bidang Ekomomi dan Pemberdayaan Masyarakat}

Penyuluhan Menabung Sejak Dini dan Praktik Ekonomi Kreatif, Dengan dilaksanakannya Penyuluhan Menabung Sejak Dini dan Praktik Ekonomi Kreatif siswa-siswi sekolah dasar mengetahui manfaat menabung dan memotivasi siswa-siswi untuk menabung guna mengatur keuangan diri sendiri dan melatih kreatifitas siswa-siswi tersebut.

\section{Bidang Kesehatan dan Lingkungan}

Senam Sehat, Dengan dilaksanakannya Senam Sehat di RW 07 desa Cibatok Dua masyarakat menjadi lebih antusias terhadap kegiatan olahraga.

Penyuluhan CTPS (Cuci Tangan Pakai Sabun), Dengan dilaksanakannya Penyuluhan CTPS

Siswa-siswi SDN Cibatok 02 dan MI Sirojusshibyan menjadi lebih paham manfaat dari mencuci tangan dan cara mencuci tangan dengan sabun yang baik dan benar, sehingga dapat mengurangi terjangkitnya penyakit yang disebabkan oleh kuman dan bakteri.

Penanaman 1000 bibit pohon, dengan maksud dan tujuan program ini, untuk menambah penghijauan lingkungan yang ada di desa Cibatok 02 dan menjadi penunjang kemandirian penghasilan dari hasil penanaman 1000 bibit pohon buah dan pohon.

Penyuluhan Pola Makan Sehat Ibu Hamil, dengan maksud dan tujuan program ini, agar ibu hamil mampu mengetahui jenis makanan yang sehat untuk dikonsumsi oleh ibu hamil dan untuk bisa menghindari jenis makanan yang tidak sehat.

\section{Bidang Pendidikan}

Bimbingan Belajar (Bahasa Inggris, Matematika)

Guna menambah wawasan dan pengetahuan para siswa/siswi untuk meningkatkan prestasi dalam bidang pendidikan.

Optimalisasi Metode Pengajaran dengan Metode "Belajar Sambil Bermain"

Dalam mewujudkan keaktifan siswa pada saat kegiatan belajar serta meningkatkan semangat belajar siswa untuk meraih prestasi.

\section{Bimbingan Ibadah Amaliah}

Guna memperdalam ilmu agama dalam ibadah amaliah sehari-hari untuk meningkatkan kualitas ibadah, yang sasarannya adalah anak-anak kisaran usia 7-11 tahun yang rumahnya berdekatan dengan posko KKN 25.

\section{Bidang Teknik}

\section{Edukasi Teknologi Informasi Komputer}

Mengenalkan dasar-dasar aplikasi kompoter agar peserta didik dapat mengikuti perkembangan teknologi informasi komputer dan mengetahui 
dampak positif serta negatif dari penggunaan komputer.

\section{SARAN}

Saran kami kelompok KKN 25 kepada pihak Desa Cibatok 02, antara lain: sampah akhir dalam lingkup tingkat kampung.

1. Mengajukan ke Dinas Lingkungan Hidup untuk pelayanan pengangkutan sampah dan menyedikan tempat

\section{REFERENSI}

Administrasi Profil Desa Cibatok Dua

Bimo, Widhi Aryo. Dkk. Maret 2018. Moralitas, Integritas dan Kreatifitas di Kampung Iwul.

2. Perbaikan saluran /selokan air yang terdapat pada setiap pinggiran rumah warga guna memperlancar aliran air yang telah digunakan oleh setiap warga.

Fahmi eroby, 2008, Pendidikan berbasis masyarakat. Yogyakarta

LPPM; Universitas Ibn Khaldun Bogor; (2018). Petunjuk Pelaksanaan KKN Tematik Terintegrasi 2018. 